International Journal of Current Advanced Research

ISSN: O: 2319-6475, ISSN: P: 2319 - 6505, Impact Factor: SJIF: 5.995

Available Online at www.journalijcar.org

Volume 6; Issue 4; April 2017; Page No. 3524-3526

DOI: http://dx.doi.org/10.24327/ijcar.2017.3526.0307

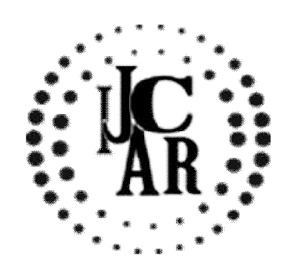

Research Article

\title{
TREATMENT OUTCOME OF PATIENTS WITH DELAYED SPUTUM CONVERSION IN CATEGORY-1 ANTI- TUBERCULOSIS TREATMENT IN CENTRAL KERALA
}

\author{
Ponnu Jose ${ }^{1 *}$., Nileena Koshy ${ }^{2}$., Priyanka ${ }^{3}$ and Jubina Bency AT $^{4}$
}

1,3,4Department of Community Medicine, Jubilee Mission Medical College\&Research Institute, Thrissur 2Department of Community Medicine, Goverment Medical College Thrissur

\section{A R T I C L E I N F O}

\section{Article History:}

Received $15^{\text {th }}$ January, 2017

Received in revised form $10^{\text {th }}$ February, 2017

Accepted $22^{\text {nd }}$ March, 2017

Published online $28^{\text {th }}$ April, 2017

\section{Key words:}

Delayed Sputum Conversion, Tuberculosis

\begin{abstract}
A B S T R A C T
Introduction: Tuberculosis (TB) is a disease that has severely affected communities and nations since time immemorial. Controlling TB in India is a tremendous challenge. Delay in sputum conversion' is defined as persistent sputum smear positivity after 2 months of intensive phase of anti tuberculosis treatment Persistent positive smears are associated with unfavourable treatment outcomes. Objectives1. To study the treatment outcome of patients with delayed sputum conversion in category-1 anti- tuberculosis treatment.2.To study the clinical profile of patients with delayed sputum conversion in category-1 antituberculosis treatment

Materials and methods

Study design- prospective cohort study. Study setting- Thrissur district of central Kerala.. Study duration- 10 months. Study population The patients who had registered under Revised National Tuberculosis Control Programme (RNTCP) of Thrissur district during the first quarter of 2013 and remained sputum positive after intensive phase of anti tuberculosis treatment during the same period. Sample size -51 .

Results. Among the total 51 patients, $80.39 \%$ were males and $19.61 \%$ were females. Mean age was $51 \mathrm{yrs} \pm 13.84$.Majority had primary level of education $(57.14 \%$ )and were manual labours (48.98\%).Smokers and alcoholics formed $77.55 \%$ and $57.14 \%$ of the sample respectively. Diabetes Mellitus was detected in 13(27.1\%) of patients. The mean duration taken to diagnose tuberculosis was $41 \pm 22$ days. Treatment outcomes attained were: cured$78.43 \%$, treatment completed- $3.92 \%$, Lost to follow up $-9.8 \%$, failure $-5.88 \%$, MDR case$1.96 \%$.
\end{abstract}

Copyright $(2017$ Ponnu Jose et al. This is an open access article distributed under the Creative Commons Attribution License, which permits unrestricted use, distribution, and reproduction in any medium, provided the original work is properly cited.

\section{INTRODUCTION}

Even though India holds $17 \%$ of worlds population, India's contribution towards global burden of tuberculosis is $26 \%{ }^{1}$. Revised National Tuberculosis Control Programme of India has achieved great success in reduction of mortality morbidity and prevalence of Tuberculosis in India. In spite of these achievements, drug resistance, HIV co-infection and comorbidities like diabetes mellitus are emerging as new threats to Tuberculosis control in India. Controlling TB in India is a tremendous challenge. Delay in sputum conversion' is defined as persistent sputum smear positivity after 2 months of intensive phase of anti tuberculosis treatment Persistent positive smears are associated with unfavourable treatment outcomes. They are likely to transmit the disease to contacts and also require extension of their initial phase for one more month. They are at increased risk of relapse and failure which puts them at risk of developing acquired drug resistance.

*Corresponding author: Ponnu Jose

Department of Community Medicine, Jubilee Mission Medical College\&Research Institute, Thrissur
A longer duration of treatment is associated with non compliance of patients with treatment, which is also another risk factor for developing drug resistant tuberculosis. WHO recommends its use as a useful indicator for monitoring the performance of TB control program.

\section{Objectives}

1. To study the treatment outcome of patients with delayed sputum conversion in category-1 antituberculosis treatment.

2. To study the clinical profile of patients with delayed sputum conversion in category-1 anti- tuberculosis treatment.

\section{MATERIALS AND METHODS}

The study was a prospective cohort study, done in the district of Thrissur of central Kerala. It was done for a period of 10 months. The category-1 tuberculosis patients registered under Revised National Tuberculosis Control Programme (RNTCP) of Thrissur district during the first quarter of 2013 were 
selected. There were 276 patients registered under RNTCP during this period. These patients were distributed among six tuberculosis units (TU) of Thrissur district. Among these patients those who remained sputum positive after intensive phase of anti tuberculosis treatment were taken as study subjects. There were 51 patients with delayed sputum conversion. They were followed up till the completion of treatment to know their outcome. Data were collected through patient interviews using a pretested semi structured questionnaire. Final outcome was confirmed by checking patient information registers kept by their respective Senior TB Treatment Supervisor. Data was coded and entered in Microsoft excel and analysed using Epi info. The quantitave data were descriptively summarized and expressed in mean with standard deviation and the qualitative variables in percentages. Strength of association was calculated using Relative Risk with 95\% confidence level.

\section{Definition $^{2}$}

\section{Successful Outcome}

A patient whose final outcome was either cured or completed treatment had a "successful outcome" while any other outcome was classified as "unsuccessful".

\section{Cured}

Initially sputum smear positive patient who has completed treatment and had negative sputum smears on two occasions, one of which is at the end of the treatment is declared as cured

\section{Treatment completed}

Initially sputum smear positive patient who has completed treatment with negative smears at end of the intensive phase / two months in the continuation phase, but none at the end of treatment, the outcome is declared as treatment completed.

\section{Failure}

Any TB patient who is smear positive at five months or more after starting the treatment is considered as 'Failure'.

\section{Lost to follow up}

A patient whose treatment was interrupted for 2 consecutive months or more.

\section{Switched over to MDR-TB Treatment}

A patient who has been diagnosed as having MDR-TB by an RNTCP accredited laboratory, prior to being declared as "Failure", and is placed on the RNTCP MDR-TB treatment regimen.

\section{Ethical consideration}

This study was approved by the institutional review board at Medical College and the District Tuberculosis Centre, Thrissur. Written informed consent was obtained from all study participants

\section{RESULTS}

\section{Clinico social profile}

Among the total 51 patients, $80.39 \%$ were males and $19.61 \%$ were females. Mean age was $51 \mathrm{yrs} \pm 13.84$. Majority had primary level of education (57.14\%) and were manual labours (48.98\%). Smokers and alcoholics formed 77.55\% (Figure-1) and $57.14 \%$ of the sample respectively. No addiction was found among females. The mean duration taken to diagnose tuberculosis was $41 \pm 22$ days. Majority had cough and weight loss as initial symptom. Diabetes mellitus was diagnosed in $27.1 \%$ of patients.

Table 1 Time taken to diagnose tuberculosis

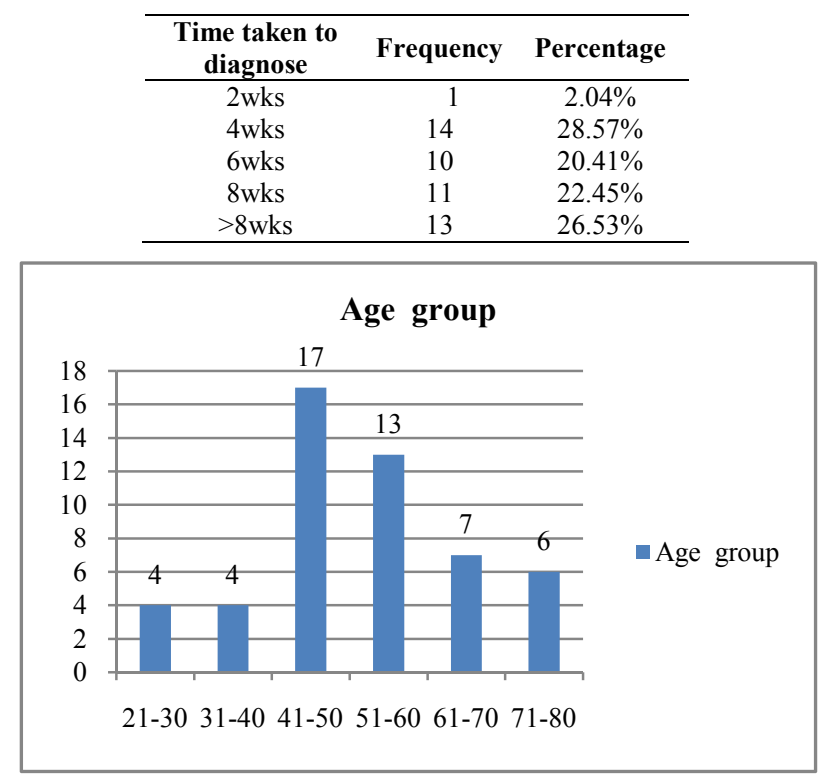

Figure 1 Distribution of patients according to age group

Patients with high sputum load $(2+$ and $3+)$ were $79.1 \%$.After intensive phase their sputum load was scanty-19(38.8\%) and $1+$ in $30(61.2 \%)$ patients. Treatment outcomes attained were: cured- $78.43 \%$, treatment completed-3.92\%, Lost to follow up- $9.8 \%$, failure $-5.88 \%$, MDR case- $1.96 \%$ (table-3) the treatment success rate was $82.35 \%$. The risk for outcomes other than 'cured' were female gender, $(\mathrm{RR}=1.76(0.372$ $8.39)$, age more than $40 \mathrm{yrs}(\mathrm{RR}=2.12(0.232-19.36)$, Diabetes Mellitus $(\mathrm{RR}=2.28(.53-9.76)$, high initial sputum load $(\mathrm{RR}=3.5(.64-18.05)$.

Table 2 Sputum load before treatment and after intensive phase of treatment

\begin{tabular}{|c|c|c|c|c|c|}
\hline \multirow{2}{*}{$\begin{array}{c}\text { Initial } \\
\text { sputum }\end{array}$} & \multicolumn{5}{|c|}{ Sputum after } \\
\hline & Freque & entage $(\%)$ & $\begin{array}{c}\text { intensive } \\
\text { phase }\end{array}$ & Freque & entage $(\%)$ \\
\hline Scanty & 2 & 4.1 & Scanty & 19 & 37.3 \\
\hline $1+$ & 9 & 18.4 & $1+$ & 23 & 45.1 \\
\hline $2+$ & 11 & 22.4 & $2+$ & 7 & 13.7 \\
\hline $3+$ & 29 & 56.9 & Not recorded & 2 & 3.92 \\
\hline Total & 51 & 100 & total & 51 & 100 \\
\hline
\end{tabular}

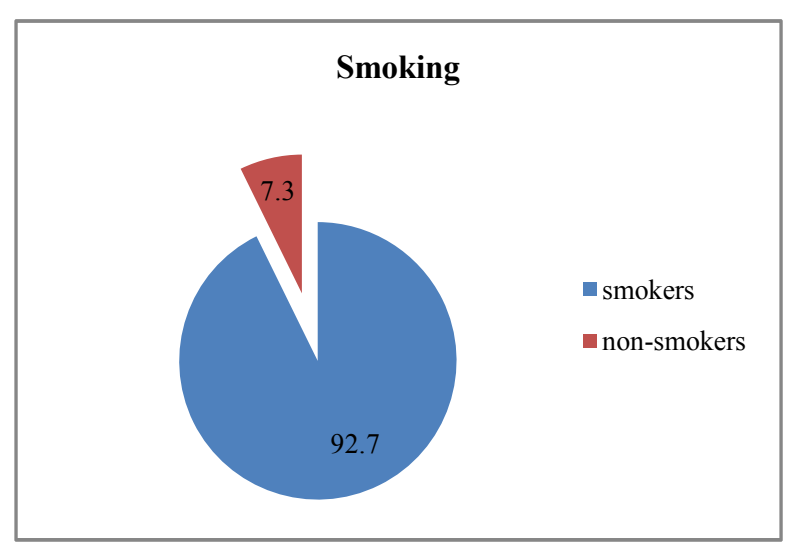

Figure 2 Smoking habits of study participants 
Table 3 Treatment outcome of patients with delayed sputum conversion

\begin{tabular}{ccc}
\hline $\begin{array}{c}\text { Treatment } \\
\text { Outcome }\end{array}$ & Frequency & Percentage(\%) \\
\hline Cured & 40 & 78.43 \\
Default & 5 & 9.80 \\
Failure & 3 & 5.88 \\
Completed & 2 & 3.92 \\
MDR & 1 & 1.96 \\
Total & 51 & 100 \\
\hline
\end{tabular}

\section{DISCUSSION}

This study is one among few studies in India that evaluated the profile and outcomes of TB patients who failed to convert after intensive phase of treatment. In India, tuberculosis affects the adults in their most productive age group i.e.15$54 \mathrm{yrs}$.In India $80 \%$ of sputum positive cases belong to this group $^{3}$, which is similar to the proportion found in the current study $(74.5 \%)$. Majority of patients $(79.3 \%)$ showed initial high sputum load $(2+$ or $3+)$. The initial high sputum load is found to be a consistent finding among patients showing delayed sputum conversion globally. ${ }^{4,5,6,7}$

Delay in diagnosing tuberculosis leads to high sputum load which in turn affect the prognosis and treatment outcome ${ }^{8,9}$. The mean duration taken to diagnose tuberculosis was $35 \pm 22$ days while the recommendation for suspecting $\mathrm{TB}$ is two weeks. Successful outcome among the patients were $41 \pm 22$ days which is near to the outcome of patients without delayed conversion. The successful outcome percentage in the above study is more when compared to other studies in Boffesson, Cameroon ${ }^{10}(76.6 \%)$, Nigeria $(78.1 \%)$ but less, in the studies done in Republic of Vanuatu by Fanai S et.al ${ }^{11}(90 \%)$ and Srilanka $^{12}(92 \%)$. Default though less $5(9.80 \%)$ need to be addressed as it denotes the need for increasing awareness regarding importance of regular drug intake. The suspected risk for outcomes other than 'cured' were female gender, $(\mathrm{RR}=1.76,95 \% \mathrm{CI}=$, age more than 40yrs $(\mathrm{RR}=2.12)$, Diabetes Mellitus ( $R R=3.4)$, high initial sputum load $(R R=2.1)$.but none showed significant relation in any statistical tests.

The treatment outcome showed good result which in turn shows the well implemented and well monitored services from the health care providers in the district

\section{CONCLUSION}

The study was done in Kerala, a state in India with the best health care policies and services. Revised National Tuberculosis Control Programme (RNTCP) has achieved great success in reduction of morbidity and mortality of Tuberculosis in Kerala. In the current study the treatment success rate was $82.35 \%$ which was similar to the outcome observed among patients with normal sputum conversion after intensive phase of treatment. 'Default'was 9.8\%, failure $5.88 \%$, MDR case- $1.96 \%$. The suspected risk factors for outcomes other than 'cured' were female gender, age more than 40yrs, Diabetes Mellitus, high initial sputum load, but none showed significant relation in any statistical tests.

\section{Recommentation}

Health education should be strengthened to the patients regarding importance of treatment, its course and duration with special mention about the need for smoking cessations. Physicians, both from private and government sectors must be recommended to strictly follow treatment algorithm for diagnosis. Disease can be suspected if presenting with typical symptoms even before 2 weeks. Co morbidities with tuberculosis especially diabetes mellitus should be monitored strictly. More detailed studies with large cohorts are required in this area to throw light into the hidden areas of delayed sputum conversion in some patients.

\section{Limitation}

Sample size was less. Dietary assessment of patients not done.

\section{References}

1. TB India 2014. Revised National TB Control Programme. Annual status report 2014. Central TB Division. Directorate General of Health Services.

2. Ministry of Health and Family Welfare, NirmanBhavan, New Delhi-110108.Available from: URL: www.Tbcindia. nic.in

3. Managing the RNTCP in your area - A Training course (module1-4)(PDF). Revised National TB Control Programme. Central TB Division. Directorate General of Health Service.Page 84. Available from:http:// tbcindia.nic.in/showfile.php?lid=2907

4. K Park. Park's textbook of Preventive and Social Medicine. $23^{\text {rd }}$ Ed. M/s Banarasidas Bhanot publishers. Jabalpur; 2011. P 178

5. Jayakody W, Harries A D, Malhotra S, et al. Characteristics and outcomes of tuberculosis patients who fail to smear convert at two months in Sri Lanka. Public Health Action 2013; 3: 26-30.

6. Singla R, Osman M M, Khan N, et al. factors predicting sputum smear positivity among pulmonary tuberculosis patients 2 months after treatment. Int $J$ Tuberc Lung Dis 2003; 7: 58-64

7. Dominguez-Castellano A, Muniain M A, Rodriguez-Bano J, et al. Factors associated with time to sputum smear conversion in active pulmonary tuberculosis. Int $J$ Tuberc Lung Dis 2003; 7: 432-438.

8. Tiwari S, Kumar A, Kapoor S K. Relationship between sputum smear grading and smear conversion rate and treatment outcome in the patients of pulmonary tuberculosis undergoing DOTS-a prospective cohort study. Indian $J$ Tuberc 2012; 59: 135-140.

9. Gopi PG, Chandrasekaran V, Subramani R, Santha T, Thomas A, Selvakumar N, et-al. Association of conversion $\&$ cure with initial smear grading among new smear positive pulmonary tuberculosis patients treated with Category I regimen. Indian J Med Res. 2006;123:807-14

10. Rajpal S, Dhingra VK, Aggarwal JK. Sputum grading as predictor of treatment outcome in pulmonary tuberculosis. Indian J Tuberc 2002, 49: 139-41.

11. Ukwaja KN, Oshi DC, Oshi SN, Alobu I. Profile and treatment outcome of smear positive TB patients who failed to smear convert after 2 months of treatment in Nigeria. Trans R Soc Trop Med Hyg. 2014;108(7):431-8

12. Fanai S, Viney K, Tarivonda L, Roseveare C, Tagaro M, Marais BJ. Profile of tuberculosis patients with delayed sputum smear conversion in the Pacific island of Vanuatu. Public Health Action. 2014; 4 Suppl 1:19-24.

13. Jayakody W, Harries A D, Malhotra S et al. Characteristics and outcomes of tuberculosis patients who fail to smear convert at two months in Sri Lanka. Public Health Action. 2013;3:26-30 